\title{
Temperature influence on mobility and charge density model of photovoltaic cells
}

\author{
J. S. T. Souza ${ }^{1}$, N. C. A. de Sousa*1@ \\ ${ }^{1}$ Universidade Federal do Oeste da Bahia, Multidisciplinar de Bom Jesus da Lapa Bom Jesus da Lapa, BA, Brasil
}

Received on October 02, 2018; Revised on November 07, 2018; Accepted on December 30, 2018.

\begin{abstract}
Photovoltaic (PV) devices that capture the energy provided by the sun have great potential as renewable energy sources. However, the input parameters such as the luminous intensity and temperature of the solar cells tend to influence the operating characteristics in the solar panels. The inherent physical processes that cannot be altered limit the efficiency of photovoltaic cells, as well as temperatures above the ideal value of operation. We propose a diode model to represent a PV cell, presenting good approximation for a commercial silicon cell. In this work we report the model with the aid of Coughey Thoma's equation to obtain the results, which indicate decrease in the mobility of loads and subsequently evaluation in terms of the load carrier diffusion lengths in regions with ideal temperatures between $293.15 \mathrm{~K}$ to $301.15 \mathrm{~K}\left(20^{\circ} \mathrm{C}\right.$ and $\left.28^{\circ} \mathrm{C}\right)$. Results were compared with local temperature between $298.15 \mathrm{~K}$ at $308.15 \mathrm{~K}\left(25^{\circ} \mathrm{C}\right.$ and $\left.35^{\circ} \mathrm{C}\right)$, in a region with a PV plant in operation in the West of Bahia. Keywords: Photovoltaic, Charge Mobility, Modeling, Temperature.
\end{abstract}

\section{Introduction}

The most commonly used energy models are being questioned as humanity is confronted with the consequences of expensive and less reliable energy systems [1]. With increasing energy demand, photovoltaic technology is one of the most promising for low-power distributed electric generation. Photovoltaics representa viable solution found for the growing increase in energy consumption. Among various applications and the need for photovoltaic energy, the power supply of electric cars is one of the most promising. With the increase in the fleet of electric cars, photovoltaic energy comes as an option to supply the need for electricity generation, considering not only its cost of production but also minimized environmental impacts [2].

In this sense, new studies are needed for the development of more efficient photovoltaic cells [3]. The theoretical models that represent the conversion of solar energy into electrical energy are necessary for process compression, providing the analysis of the effects caused by external variables. In the standard test conditions for photovoltaic cells, we have solar radiation of $1000 \mathrm{~W} / \mathrm{m}^{2}$, cell temperature of $25^{\circ} \mathrm{C}$ and air mass 1.5 [4].

The performance of the photovoltaic modules is influenced mainly by the luminous intensity and temperature of the cells, leading to the reduction of charge mobility, consequently, decreasing their efficiency. Thus, the addition of external factors in the photovoltaic device, such as the variation in local temperature, will correspond to

*Endereço de correspondência: nuccia.sousa@ufob.edu.br. a model that is closer to the real conditions and that directly affects its efficiency [5].

For the model the silicon photovoltaic cell, formed of p-n junction semiconductor material in Fig. 1.

The energy generation process starts at the moment a photon with energy equal to or greater than the forbidden bandwidth, the energy gap (Eg) of the material, falls on the cell. An electron-hole pair is created if the diffusion length $\mathrm{L}$ of the charge carrier is large enough that the photon is directed to the depletion region (space charge region). The charge will be accelerated by the electric field to the opposite region of the one created. The position in which these pairs are created depends exclusively on the absorption coefficient of the semiconductor material [6].

This property determines that photons with energy much greater than (Eg) will create charge carriers in the region of the emitter and, in approaching the value of the gap, the carrier will be generated in deeper locations of the base region. Therefore, the cell becomes transparent

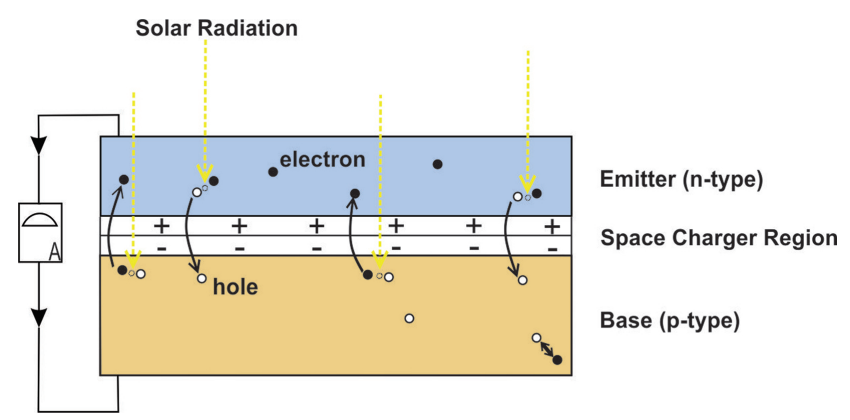

Figure 1: llustration of semiconductor structure of silicon. 
to photons with energy lower than $(\mathrm{Eg})$. This process of separation of photogenerated charges creates a potential difference between the transmitter and the base [4].

If the circuit is closed between the emitter and the base, an electric current will flow through the connection and will remain as long as the incidence of light radiation is available. The photogenerated current $I_{L}$ is due to the collective motion of electron-hole pairs generated by the absorbed photons. With the separation of the charge carriers from the $\mathrm{p}-\mathrm{n}$ junction the photovoltaic effect originates; this effect resembles that of any semiconductor diode exposed to radiation, so the photovoltaic cell will be understood as a diode [7].

It is possible to represent the charge mobility in a silicon cell using the equations of Coughey Thomas [8], used together with the coefficient of dependence of temperature. These empirical equations present a good approximation for a commercial silicon cell, considering the type of dopant impurity, its concentration and temperature variations.

\section{Mathematical Model}

The basic process of power generation can be summarized in the circuit shown in Fig. 2. The circuit has a current source $I_{L}$ representing the current generated by photogenerated charge carriers, having a sufficient diffusion length to reach the depletion region. In parallel to the $I_{L}$, there is a diode providing a path for the photogenerated current that does not arrive at the load, $I_{D}$; this current represents the pairs that did not have enough diffusion length and it is equivalent to the generated electron that recombines itself in the valence band before the separation of charges $[5,6]$.

Real cells have some structural and physical factors that influence their energy production. These factors end up acting as resistors that are in series $R_{S}$ and in parallel $R_{P}$ with the cell. The resistances are due to the resistive elements found by the photogenerated current because of the defects at the p-n junction and in the formation of the crystals in the manufacturing process of the device $[4,9]$.

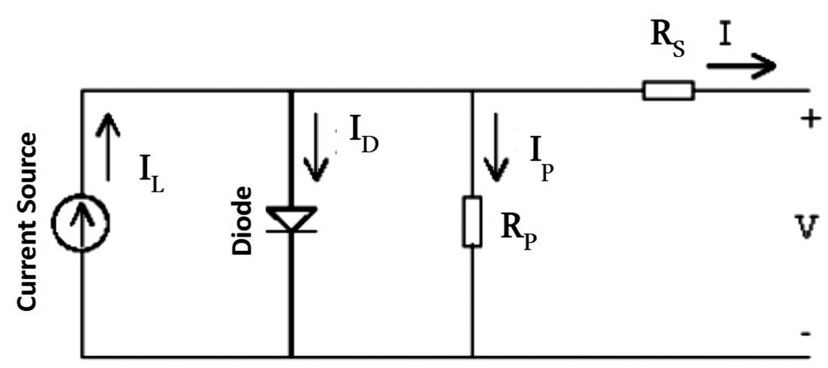

Figure 2: Equivalent circuit -1 diode model.
We apply Kirchhoff's law to describe the currents in the electric circuit of Fig. 2,

$$
I_{L}=I_{D}+I_{R p}+I_{R S}
$$

By inspection of Equation 1, it is observed that in the dark $\left(I_{L}=0\right)$ the photovoltaic cell has the same behavior as a diode [10]. We have that the current in the diode $I_{D}$ is defined in Equation 2.

$$
I_{D}=I_{\text {sat }}\left[e^{q /(n k T c)}\right]-1
$$

Where $I_{\text {sat }}$ is the reverse saturation current, $q$ is the charge of the electron, $n$ is the diode ideality factor, $k$ is the Boltzmann constant and $T_{c}$ is the cell temperature in absolute scale.

It is possible, through the reverse saturation current, to access the material properties and details of the construction of the p-n junction. Equation 3 is a function of thermal equilibrium between the concentrations of the minor carriers of the $\mathrm{p}-\mathrm{n}$ junction [11].

$$
I_{\text {sat }}=q n_{i}^{2}\left(\frac{D_{n}}{L_{n} N_{a}}+\frac{D_{p}}{L_{p} N_{d}}\right)
$$

$D_{n}$ and $D_{p}$-diffusivity of hole and electrons of the material of type $\mathrm{n}$ and $\mathrm{p}$;

$L_{n}$ and $L_{p}$-diffusion length hole and electrons of type $\mathrm{n}$ and type $\mathrm{p}$ respectively;

$N_{a}$ and $N_{d}$-concentration of acceptors in the p-type region and concentration of donors in the n-type region.

The concentrations of charge carriers are proportional to the intrinsic concentration of carriers $\left(n_{i}\right)$, Equation $4[12]$.

$$
n_{i}^{2}=n_{\nu} n_{c} e^{\frac{E_{q}}{\left(k T_{c}\right)}}
$$

In which $n_{v}$ is the density of states with energy in the valence band, $n_{c}$ is the density of states with energy in the conduction band, Eg the energy gap of criytalline silicon equal to $1.12 \mathrm{eV}$. The values of $n_{c}$ and $n_{v}$ can be calculated by Equations 5 and 6 , which show a contribution of $T^{3 / 2}$ in the variation and $n_{i}$

$$
\begin{aligned}
& n_{c}=2\left(\frac{2 \pi m_{e}^{*} k T c}{h^{2}}\right)^{3 / 2} \\
& n_{\nu}=2\left(\frac{2 \pi m_{p}^{*} k T c}{h^{2}}\right)^{3 / 2}
\end{aligned}
$$

We have that $m_{e}$ and $m_{p}$ are the effective masses of the electron and holes, and h the Planck constant.

In the dynamics of electrons and holes in photovoltaic cells, we can start from the semiconductor model based on the dynamics of electric charge carriers. Nothing but electrons and holes, as we propose, where the collective motion of these charges results in electric current. The diffusivity of the material can be calculated as Equation 7 shows [11],

$$
D_{n, p}=\frac{K T_{c}}{q} \mu_{n, p}
$$


Being the values of $n$ and $p$ are the mobility of the charge, electron and hole carriers respectively, Equations 8 to 12 are described below.

Among the parameters analyzed in the current in the dark, mobility is a feature of extreme influence since it defines the performance of the load carrier when moving through the material $[13,14]$.

For mobility modeling, it was used the equation set of Coughey Thomas [8], together with the coefficient of dependence with temperature. These empirical equations present a good approximation for a silicon cell, considering the type of dopant impurity, its concentration and temperature variation of the $T_{c}$ cell.

$$
\begin{gathered}
\mu_{m}=\mu_{m}^{m i n}+\frac{\mu_{m}^{L}-\mu_{m}^{m i n}}{1+\left(\frac{N_{m}}{N_{m}^{r e f}}\right)^{a_{m}}} \\
\mu_{m}^{L}=\mu_{m, 300}^{L}\left(\frac{T_{c}}{300}\right)^{y_{0, m}} \\
\mu_{m}^{m i n}=\mu_{m, 300}^{m i n}\left(\frac{T_{c}}{300}\right)^{y_{1, m}} \\
N_{m}^{r e f}=N_{m, 300}^{r e f}\left(\frac{T_{c}}{300}\right)^{y_{3, m}} \\
a_{m}=a_{m, 300}\left(\frac{T_{c}}{300}\right)^{y_{4, m}}
\end{gathered}
$$

The factors of the above equations are listed in Table 1, taken from the same reference as Equations 8 to 12, where $\mathrm{m}$ is the type of dopant material (type $\mathrm{n}$ or type p).

For this work the n-type dopant concentration of $N_{d}=10^{18} \mathrm{~cm}^{-3}$ and p-type of $N_{a}=10^{16} \mathrm{~cm}^{-3}$ was determined.

$\tau_{n}$ and $\tau_{p}$ are the average times that electrons and holes move before they recombine. The average recombination time in conjunction with the dopant concentration determines the diffusion length of the material, with values calculated based on Equations 13 and 14 [16, 17].

$$
\begin{aligned}
\tau_{n} & =\frac{1}{\left(3.45 \times 10^{-12} N a\right)+\left(9.5 \times 10^{-32} N_{a}^{2}\right)} \\
\tau_{p} & =\frac{1}{\left(7.8 \times 10^{-13} N d\right)+\left(9.5 \times 10^{-31} N_{d}^{2}\right)}
\end{aligned}
$$

\begin{tabular}{|c|c|}
\hline Parameter $(\mathbf{m}=\mathbf{n})$ & Parameter $(\mathbf{m}=\mathbf{p})$ \\
\hline$\mu_{\mathrm{m}, 300}^{\mathrm{L}}=5300 \mathrm{~cm}^{2} / \mathrm{Vs}$ & $\mu_{p, 300}^{L}=200 \mathrm{~cm}^{2} / V s$ \\
\hline yo,, $\mathbf{n}=-19$ & $y_{0, p}=-1.2$ \\
\hline$b m \mu_{\mathbf{n}, 300}^{\min }=1520 \mathrm{~cm}^{2} / \mathrm{Vs}$ & $\mu_{p, 300}^{\min }=24 \mathrm{~cm}^{2} / V s$ \\
\hline $\mathrm{y}_{1, \mathrm{n}}=\mathbf{2}$ & $y_{1, p}=1.2$ \\
\hline $\mathrm{N}_{\mathrm{d}, 300}^{\mathrm{ref}}=64 \times 10^{16} \mathrm{~cm}^{-3}$ & $N_{a, 300}^{r e f}=2.5 \times 10^{17} \mathrm{~cm}^{-3}$ \\
\hline $\mathrm{y}_{3, \mathbf{n}}=\mathbf{3 7}$ & $y_{3, p}=0.47$ \\
\hline$a_{n, 300}=05$ & $a_{p, 300}=1$ \\
\hline $\mathbf{y}_{4, n}=\mathbf{0}$ & $y_{4, p}=0$ \\
\hline
\end{tabular}

Table 1: Parameters for calculation of the mobility, type $n$ dopant: Phosphorus and type p dopant: Indium [15].
These equations present a good approximation of the values described experimentally in the literature, since they are constructed by making approximations based on experimental observations [17].

For the calculation of diffusion length Equation 15 is used; in fact, two equations, one for $\mathrm{p}$ and one for $\mathrm{n}$ [18].

$$
L_{n, p}=\sqrt{D_{n, p} \tau_{n, p}}
$$

The parameters in the equations of the proposed model are related to the operating conditions and important for operation analysis, when the incident radiation and temperature on a cell varies. Therefore, the short-circuit current and the open circuit voltage also suffer variations affecting operating efficiency.

\section{Results and Discussion}

From Equation 4 it was possible to construct the graph shown in Fig. 3.

The commonly accepted value for the intrinsic concentration for $300 \mathrm{~K}$ silicon is $1.5 \times 10^{10} \mathrm{~cm}^{-3}$, but, by calculating the concentration using Equation 4, the value found is $6.9 \times 10^{9} \mathrm{~cm}^{-3}$. This discrepancy is due to some factors, for example the effective mass $m_{e}{ }^{*}$ and $m_{p}{ }^{*}$ are values obtained experimentally and since the effective mass is the measure of how well a particle moves in a crystal, this parameter may have a slight dependence on the interactions with ionic nuclei of the crystalline lattice [19].

In addition, the state density function for a semiconductor was obtained by the Sommerfeld electron gas theory, which takes into account the confinement limits of the charge carrier, treating it free of any force, being equivalent to the well of infinite square potential [20].

Thus, this theoretical expression may not agree exactly with experimental observations. The difference between the experimental result is approximately a factor of 2 ,

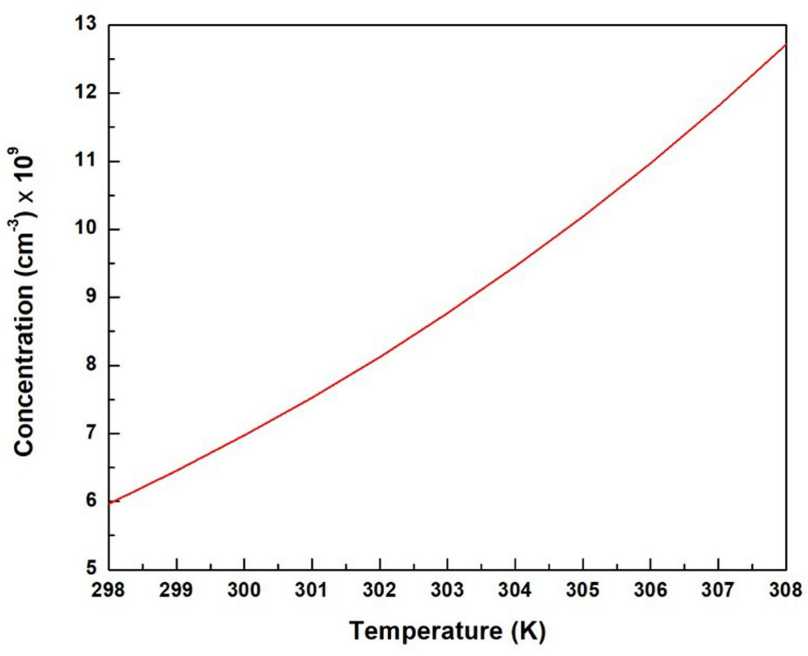

Figure 3: Variation of intrinsic concentration with temperature. 
which in many cases does not represent a significant discrepancy [19].

The Fig. 4 shows that for a n-type doped with $10^{12}$ $\mathrm{cm}^{-3} \mathrm{P}$ (phosphorus) atoms, with a temperature variation of $10 \mathrm{~K}$, a decrease in mobility of $370 \mathrm{~cm}^{2} / \mathrm{Vs}$.

For the p-type material shown in Fig. 5, with the concentration of $10^{12} \mathrm{~cm}^{-3}$ In (Indium) atoms subjected to the same temperature variation the mobility decreases about $9.6 \mathrm{~cm}^{2} / \mathrm{Vs}$.

The results in Fig. 4 and 5 show the behavior of carrier mobility in two situations. The first is for a region where the temperature varies from $293.15 \mathrm{~K}$ to $301.15 \mathrm{~K}$ (20 ${ }^{\circ} \mathrm{C}$ to $28^{\circ} \mathrm{C}$ );

The second situation is for regions in Brazil with high irradiance rates, according to the Solarimmetric Atlas [21], and present an average variation of the ambient temperature of $298.15 \mathrm{~K}$ to $308.15 \mathrm{~K}\left(25{ }^{\circ} \mathrm{C}\right.$ to $\left.35{ }^{\circ} \mathrm{C}\right)$ throughout the year, according to the National Institute of Meteorology. It is observed that both the mobility

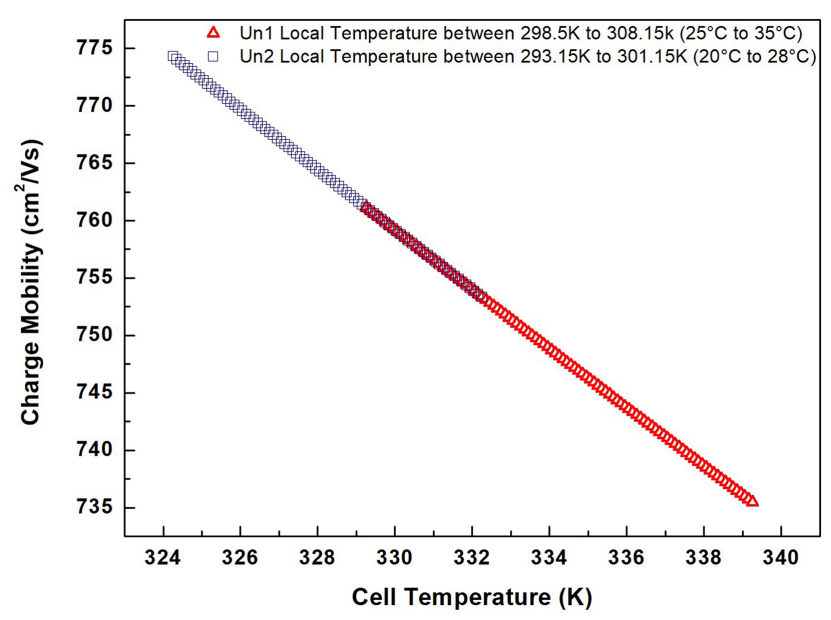

Figure 4: Mobility of carriers of type $\mathrm{n}$ with different temperatures.

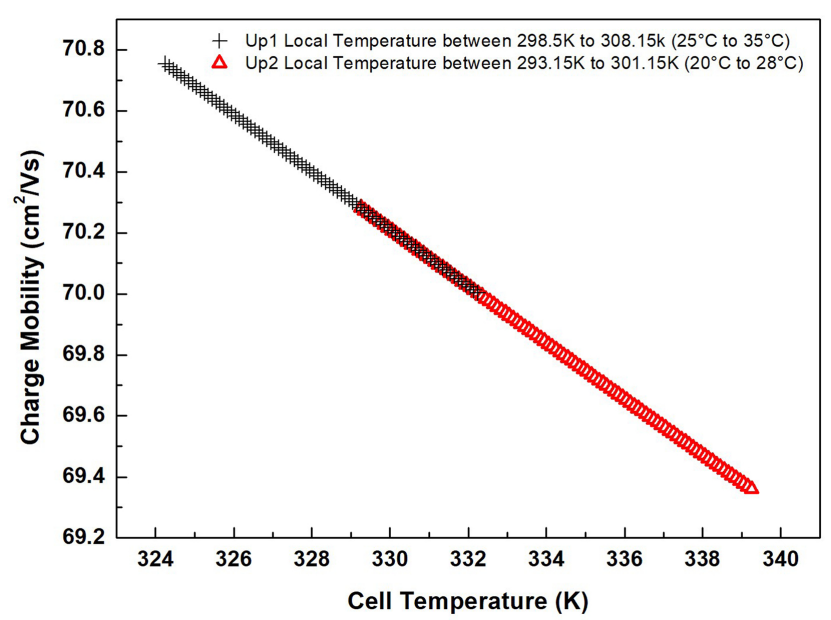

Figure 5: Mobility of carriers of type $p$ with different temperatures. of n-type and p-type carriers undergo the influence of temperature increase.

The concentration of dopant impurities is extremely relevant regarding the variation of

mobility with temperature variation. It is represented in Fig.6, for $\mathrm{n}$-type material $\mathrm{n}$ with temperature variation of $15 \mathrm{~K}(313 \mathrm{~K}-298 \mathrm{~K})$, with doping of $10^{12} \mathrm{~cm}^{-3}$. The mobility presented a variation of approximately 506.51 $\mathrm{cm}^{2} / \mathrm{Vs}$.

In the same figure, with dopant concentration of $10^{18}$ $\mathrm{cm}^{-3}$, mobility varied about $91.96 \mathrm{~cm}^{2} / \mathrm{Vs}$ in the same temperature range.

In another analysis (Fig. 7), in the dopant p-type material at a temperature range of $15 \mathrm{~K}(313 \mathrm{~K}-298 \mathrm{~K})$, with dopant concentration of $10^{12} \mathrm{~cm}^{-3}$, the mobility varied about $12.414 \mathrm{~cm}^{2} / \mathrm{Vs}$. At a concentration of $10^{18} \mathrm{~cm}^{-3}$, the mobility varied approximately $1.656 \mathrm{~cm}^{2} / \mathrm{Vs}$

The results are similar to the model of solar cells found in the literature, with convenient use of the measured

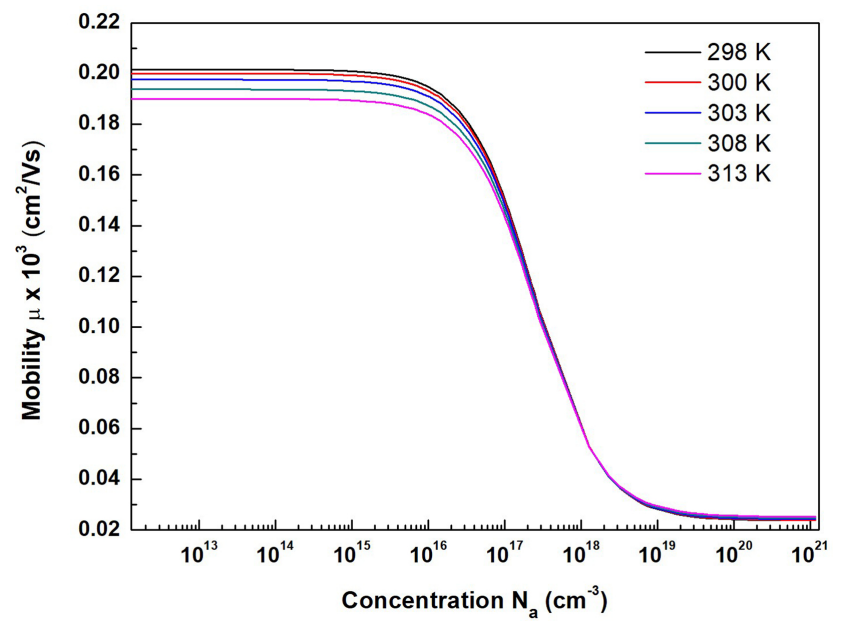

Figure 6: Mobility of n-type carriers with different doping at different temperatures.

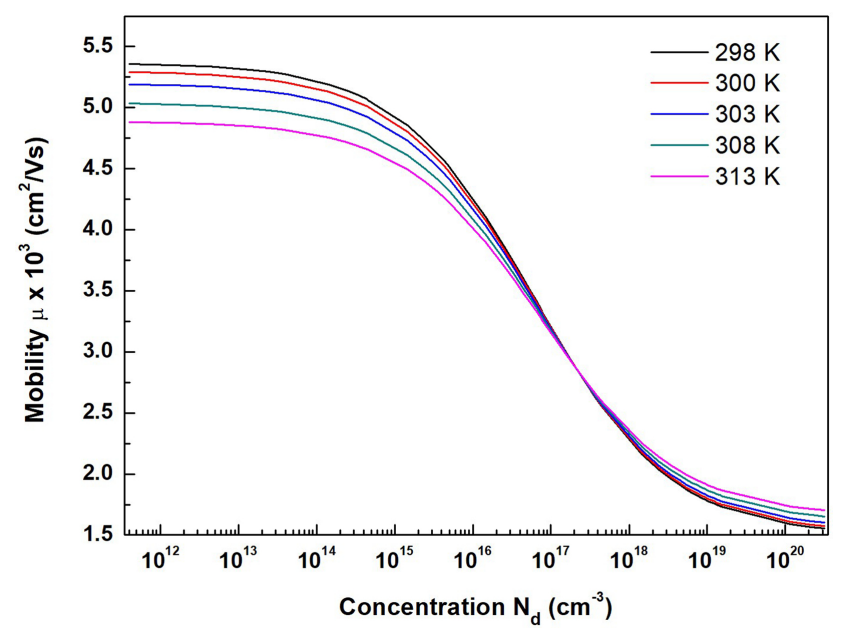

Figure 7: Mobility of p-type carriers with different doping at different temperatures. 
data or empirical formulas, for operations mobilities in $300 \mathrm{~K} \mathrm{Si}$ are well approximated [22].

This phenomenon occurs due to two physical processes that influence the mobility of the load carrier. The first process is the thermal scattering, due to the collisions of the electrons with phonons of the network, since the atoms of the vibratory network have determined thermal energy in temperatures above $0 \mathrm{~K}$. A variation in the network temperature causes the atoms to randomly vibrate by the crystal and consequently interrupt the periodic potential that the crystalline lattice possesses. The second process is scattering by ionizing impurities, since the dopants in the lattice will be ionized at room temperature. Coulomb interactions between free electrons in the network and the ionic nuclei of the impurities will be initiated, with this being an independent process of temperature oscillations as soon as it has values above the energy required for the ionization of the atoms [23].

In this work, the mobility variation for commercial Si-c cells, which have p-type dopant concentration of $10^{15} \mathrm{~cm}^{-3}$ to $10^{16} \mathrm{~cm}^{-3}$ and type $\mathrm{n}$ of $10^{18} \mathrm{~cm}^{-3}$ to $10^{19}$ $\mathrm{cm}^{-3}$ are presented in detail in Fig. 8 and 9 .

Because they have high concentrations of dopants, they are located in the medium/low temperature dependence regions in the mobility range.

Although presenting low / medium covariance of mobility with temperature, the main consequence of the mobility fluctuation is the increase in the current density of reverse saturation, shown in Fig. 10, calculated from Equation 3.

Even if mobility is not explicitly present in the equation, it is presented as the main factor considering that it is the fundamental parameter for diffusivity calculation, diffusion length and recombination time of charge carriers in the photovoltaic device.

For a crystalline silicon $\mathrm{p}-\mathrm{n}$ junction the saturation current density shows an increase of approximately a

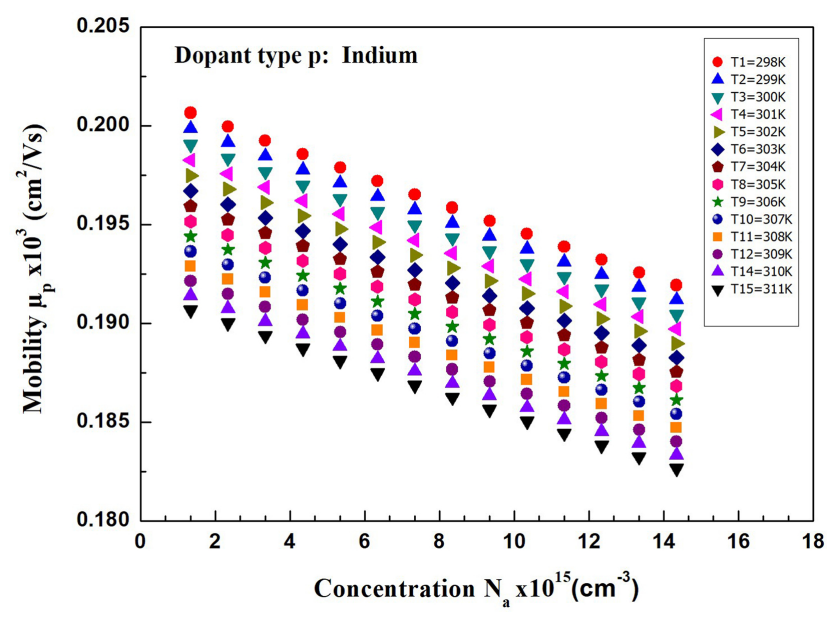

Figure 8: Mobility of the p-type charge carriers to a Si-c cell with commercial concentration of dopant at different temperatures.

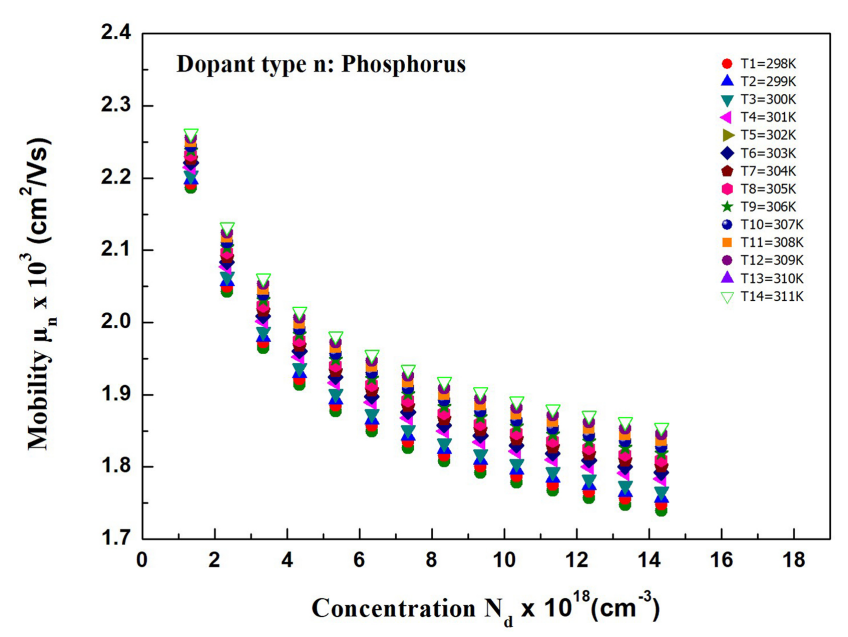

Figure 9: Mobility of n-type charge carriers to a Si-c cell with commercial concentration of dopant at different temperatures.

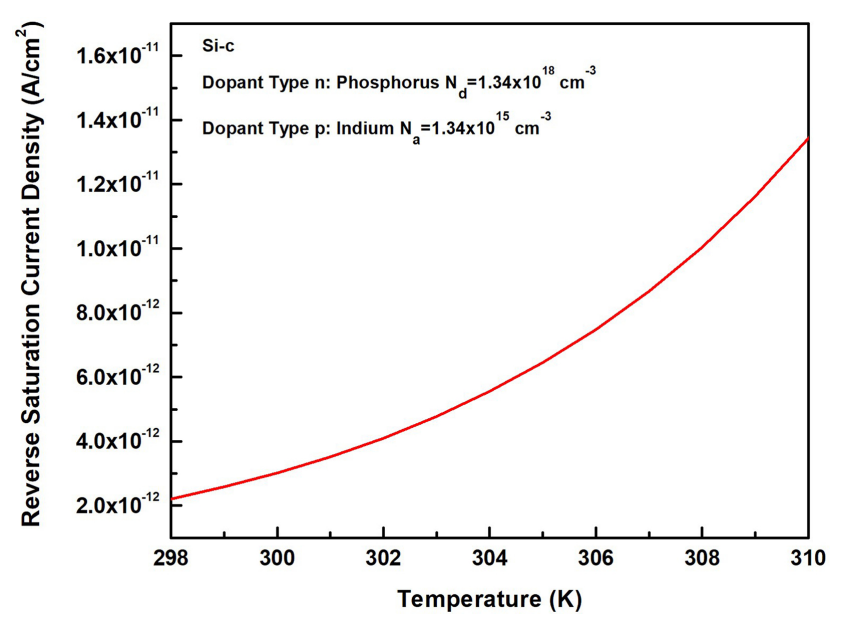

Figure 10: Mobility of n-type charge carriers to a Si-c cell with commercial concentration of dopant at different temperatures.

factor of 4 for every $10 \mathrm{~K}$ increase in temperature. Ideally the saturation current should be as low as possible.

Due to the dependence of the short-circuit current $I_{C C}(\lambda)$ on the spectral response, it is assumed that $I_{C C}$ is equivalent to $I_{L}(A / n m)$. With the previous analyzes, we can analyze the spectral response as a function of temperature.

Thus, it can be said that the equations described play an important role both in determining the efficiency of the various types of semiconductors and in the choice of the best solutions in relation to the operating temperatures of the solar cells [24].

\section{Conclusion}

In the analysis of the influence of temperatures above NOCT (Nominal Operating Cell Temperature) in the production of photovoltaic solar energy, it is verified that the mobility of charge carriers, although presenting low changes in commercial cells, from the point of view of the 
temperature variation, caused a considerable change in the $J_{\text {sat }}$ reverse saturation current density, thus substantially affecting the working efficiency of the photovoltaic device.

The data presented through the model opens space in the development of new methods that allow the modeling of the mobility in 2nd generation (thin films) and 3rd generation devices, organic cells, for a later analysis of the influence of temperature.

Ideally the saturation current should be as low as possible; its variation is a consequence of the change in mobility caused by the change in the concentration of ionized impurities and due to the increase of electron collisions with atoms of the vibration network. Both causes are directly connected to temperature variation.

Among the analyzed parameters, the charge mobility, which is related to the current in the dark, showed to be a characteristic of extreme influence; the current in the dark, which is related to the charge mobility has proved to be a characteristic of extreme influence, since it defines the performance of the load carriers when moving through the material. From the electrical parameters, the I-V curve can be determined, which characterizes the operation mode of solar cells in photovoltaic modules: open circuit voltage, short-circuit current, form factor and efficiency.

Due to the increase in the operating temperature of the device, the values indicate a power drop, because the drop of Voc to a photogenerated constant current means a drop in resistance and consequently in the power delivered by the device [25].

The model used presented a good approximation of the reality, allowing the analysis of the limitations of the silicon cell. It is possible to work with new materials with absorption coefficients that take advantage of a larger range of the solar spectrum.

\section{Agradecimentos}

Nuccia Carla thanks the support of CNPq and the Federal University of West Bahia Code: CP CMBJL 02 for the scientific scholarship granted to the student Jonathas Samuel. This work has received honorable mention of the Brazilian Physics Society.

\section{References}

[1] M.V. Flavio and M.T.C. Mansor, Química Nova 33, 757 (2009).

[2] A.Y. Saber and G.K. Venayagamoorthyr, IEEE Transactions on Industrial Electronics 58, 1229 (2011).

[3] J. Zhao, A. Wang, P. Altermatt and M.A. Green, Applied Physics Letters 66, 3636 (1995).

[4] https://www.portal-energia.com/downloads/livromanual-de-engenharia-sistemas-fotovoltaicos2014.pdf
[5] A. Luque and S. Hegedus, Handbook of Photovoltaic Science and Engineering (John Wiley \& Sons, West Sussex, 2011).

[6] V. Avrutin, N. Izyumskaya and H. Morkoç, Superlattices and Microstructures 49, 337 (2011).

[7] P. Kumar, Organic solar cells: device physics, processing, degradation, and prevention (Taylor \& Francis Group, Boca Raton, 2017).

[8] D.M. Caughey and R.E. Thomas, Proceedings of the IEEE 55, 2192 (1967).

[9] L.A.T. Grisales, C.A.R. Paja and A.J.S. Montes, Tecnura 20, 171 (2016).

[10] J. Bisquert, The physics of solar cells: perovskites, organics, and photovoltaic fundamentals (Taylor \& Francis Group, New York, 2018.)

[11] S.M. Rezende, Materiais e Dispositivos Eletônicos (Livraria da Física, São Paulo, 2015).

[12] E.M. Pell, Journal of Applied Physics 26, 658 (1955).

[13] A. Einstein, Ann. Phys. 17, 549 (1905).

[14] A. Einstein, Ann. Phys. 19, 371 (1906).

[15] S. Dhar, H. Kosina, V. Palankovski, S.E. Ungersboeck and S. Selberherr, IEEE Transactions on Electron Devices 52, 527 (2005).

[16] J.M. Dorkel and Ph. Leturcq, Solid-State Electronics 24, 821 (1981).

[17] http://www.virginiasemi. comResistivityCarrierTransportinSilicon.pdf

[18] W. Shockley, Bell Labs Technical Journal 28, 435 (1949).

[19] D. Neamen, Semiconductor Physics and Devices (McGraw-Hill, New York, 2002).

[20] E.F. Schubert, Doping in III-V Semiconductors (AT\&T Bell Laboratories, New York, 1993).

[21] T. Chigueru and N. Fraidenraich, Atlas Solarimétrico do Brasil: banco de dados solarimétricos (Ed. Universitária da UFPE, Recife, 2000).

[22] R.F. Pierret and W.N. Gerold, Modular Series on Solid State Devices: Advanced Semiconductor Fundamentals (Pearson Education, New Jersey, 1987).

[23] C. Jacoboni, C. Canali, G. Ottaviani and A.A. Quaranta, Solid-State Electronics 20, 77 (1977).

[24] N. Stem, Células Solares de Silício de Alto Rendimento: Otimizações Teóricas e Implementações Experimentais Utilizando Processos de Baixo Custo. Tese de Doutorado, Universidade de São Paulo, São Paulo (2007).

[25] N.F.W. Lima, Investigação De Algoritmos De Rastreamento Do Ponto De Máxima Potência Em Módulos Fotovoltaicos. Tese de Doutorado, Universidade de Brasília, Brasília (2014). 